\title{
Use of Dental Inlay for Treatment of Hip Joint Dysregulation: A Case Report
}

\author{
Yoshiro Fujii \\ Shin Kobe Dental Clinic, Kobe City, Japan \\ Email: shin-kobe-dentalclinic@s9.dion.ne.jp
}

Received 9 October 2015; accepted 15 November 2015; published 18 November 2015

Copyright (C) 2015 by author and Scientific Research Publishing Inc.

This work is licensed under the Creative Commons Attribution International License (CC BY). http://creativecommons.org/licenses/by/4.0/

c) (i) Open Access

\begin{abstract}
The purpose of this study was to demonstrate the improvement of hip joint dysregulation, including pain (coxalgia), tension, and restriction of joint mobility, using a dental gold alloy inlay. The subject was a 63-year-old man who was suffering from the abovementioned symptoms for several months. On placement of the gold alloy inlay on his chest, the joint flexibility was observed to increase, and the severity of the abovementioned symptoms decreased. When the inlay was placed in his tooth, the flexibility of the joint further increased, and all other symptoms disappeared. No side effects were observed, and the prognosis was good. We believe that these effects may be explained using the electromagnetic waves emitted by the inlay and by the restoration of biting conditions. Future multidisciplinary research focusing on possible underlying mechanisms regarding the relation between electromagnetic waves and dentistry is necessary.
\end{abstract}

\section{Keywords}

Hip Joint Pain, Coxalgia, Dental Inlay, Joint Flexibility, Electromagnetic Waves

\section{Introduction}

Prescription drugs, ice, and rest are considered to be effective for relieving pain in the hip joint (coxalgia) caused by a muscle or tendon sprain, whereas exercising, stretching, and physical therapy are considered to be effective in cases where arthritis is the cause. A total hip joint replacement (arthroplasty) may be considered [1] when osteoarthritis causes severe pain or deformity of the hip joint. However, to the best of our knowledge, there are several reports with regard to the affection of intra-oral bacteria on a hip joint replacement, but there are no previous reports regarding a dental treatment that was effective in treating hip joint motor conditions [2] [3]. Oral conditions, particularly occlusion, are closely associated with other parts of the body e.g., body posture, temporomandibular disorder, and cervicobrachial issues [4]-[7]. Moreover, stimulation of the buccal mucous 
membrane by modified tooth structure was shown to cause lumbago [8]. Furthermore, some substances can have a marked effect on joint mobility, even without insertion into the body, by emission of unique electromagnetic waves [9]. Although the relationship between electromagnetic waves and dentistry has been reported in multiple studies [10]-[16], the mechanism underlying this effect remains unclear. The purpose of this report was to demonstrate that hip joint symptoms, such as pain, tension, and restriction of joint movement might be relieved by unique electromagnetic waves emitted by gold alloy inlays and restoration of the subject's biting conditions.

\section{Case Report}

\section{Subject, Methods, and Result}

The subject was a 63-year-old man who was suffering from bilateral hip joint dysregulation, including pain (coxalgia), tension, and restriction of joint mobility for several months. After chiropractic treatment, his symptoms were temporarily reduced. Additionally, the subject used painkillers to treat the pain. He took no other medications for treatment of these symptoms. His right joint was severely affected and had been causing extreme pain while walking for several months. Moreover, abduction of this joint resulted in pain and tension around the groin area. The angle between the bed and his right lower thigh was approximately $30^{\circ}$ when he abducted his right hip joint (Figure 1). There was a silver inlay and secondly dental caries around it in the left lower second molar. The silver inlay and secondly dental caries were removed and we performed a cavity preparation for an inlay restoration. There was almost no effect of these procedures on his symptoms.

A gold alloy inlay (Au, 87.0\%; Pt, 11.0\%; and the rest, $\mathrm{Zn}$ and $\mathrm{Ir}$ ) was created and was judged to be effective by the Bi-Digital O-Ring Test (Figure 2) [17] [18] as follows: First, the subject's grip power decreased on stimulation of the hip joint [8]. Second, when the metal was set on his body, if his grip power did not decrease despite stimulation to the subject's hip joint, the metal was judged to be effective. When the metal inlay was placed on his chest, the hip joint revealed greater flexibility, resulting in an angle of approximately $5^{\circ}$ (Figure 3). However, some stiffness and pain still persisted. When the inlay was removed from the subject's body, the subject's leg returned to the initial position, and on placement in the left lower second molar (Figure 4), the angle decreased to almost $0^{\circ}$ (Figure 5) and neither pain nor tension remained.

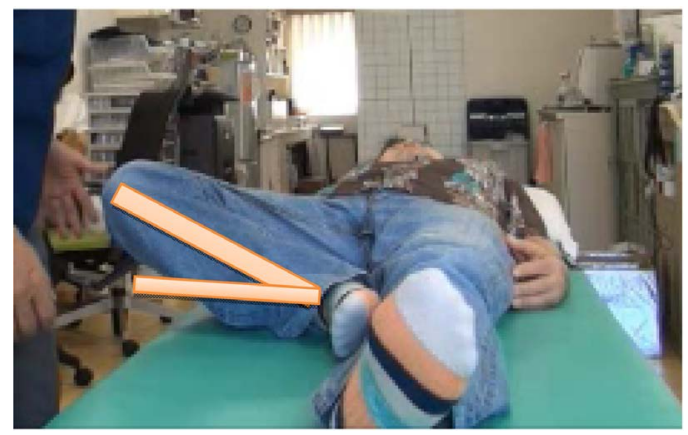

Figure 1. Before treatment, the angle between the bed and his right lower thigh was approximately $30^{\circ}$ on abduction of the right hip joint.

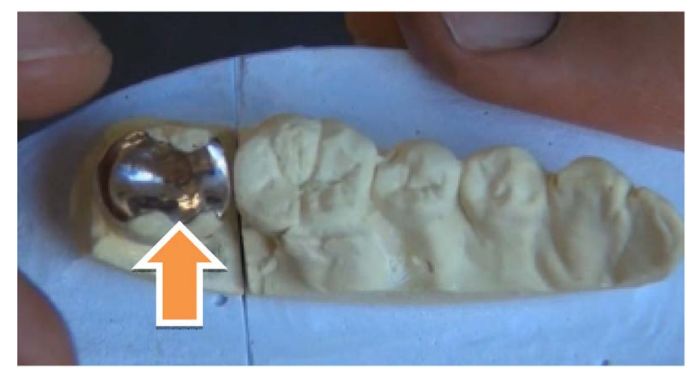

Figure 2. The gold alloy inlay (arrow) that was judged to be effective by the Bi-Digital O-Ring Test. 


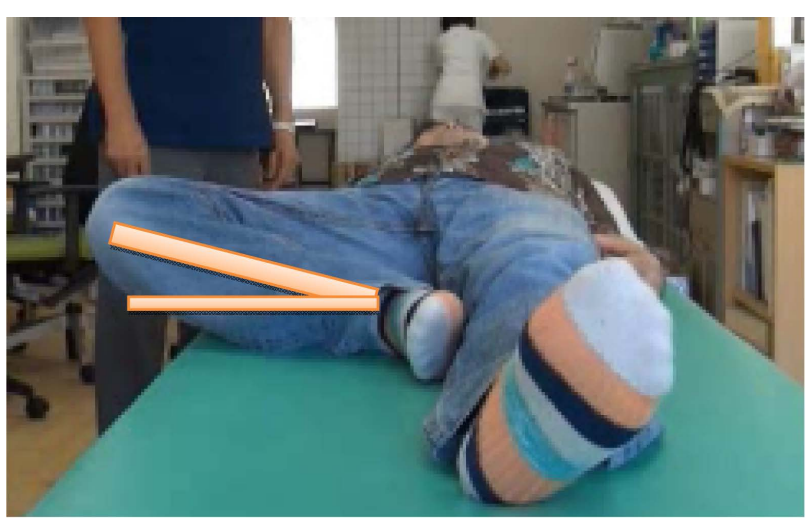

Figure 3. When the inlay was placed on the subject's chest (not seen in this figure), the hip joint revealed greater flexibility, and the angle between the bed and the lower thigh was approximately $5^{\circ}$. However, some stiffness and pain still remained.

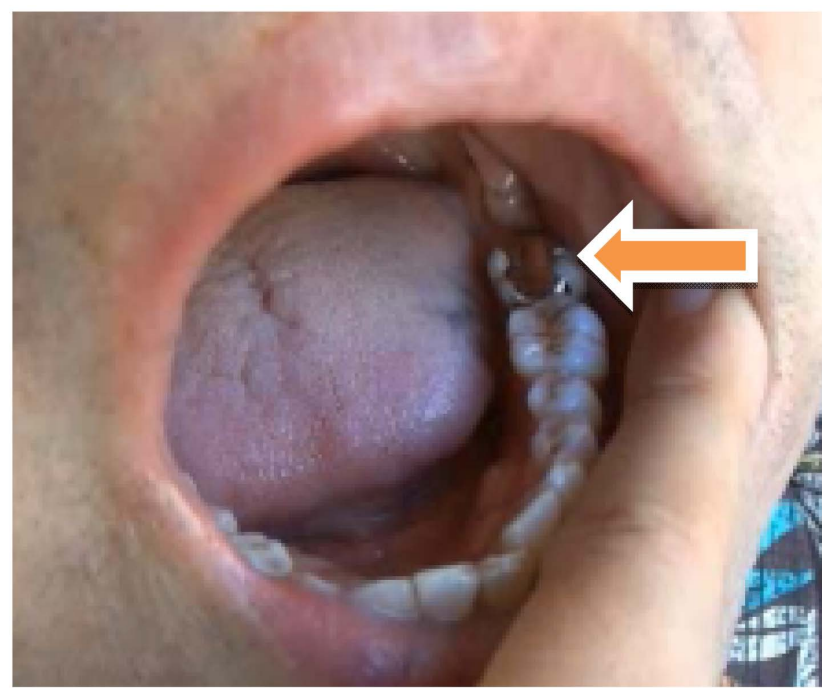

Figure 4. The inlay (arrow) was placed in the left lower second molar.

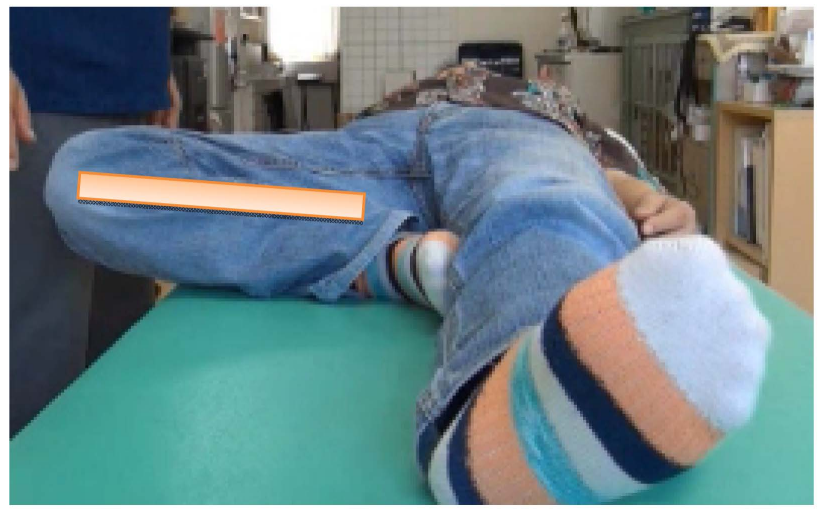

Figure 5. The angle between the bed and the subject's lower thigh was almost $0^{\circ}$ on placement of the inlay in the left lower second molar, and the subject felt neither pain nor stiffness in either of his hip joints. 
This result was lasting; furthermore, neither did symptoms reoccur nor were there any side effects.

\section{Discussion}

The results of this study demonstrated that an inlay was capable of affecting the hip joint when placed in the oral cavity and also when only placed in close proximity to the body. This effect could be explained by the fact that it generates unique electromagnetic waves and also restores biting conditions. It has been hypothesized that these waves may have played a role in improving the hip joint when the alloy was placed in close proximity to the body [7]. However, the underlining mechanism is still unclear and further research is required. It has been previously reported that harmful electromagnetic waves from cell phones and PCs may cause scoliosis, balance dysregulation, joint mobility disorders, etc. [8]-[14]. However, the results of this study demonstrated that the use of beneficial electromagnetic waves and occlusal treatment were effective methods of treatment. The inlay was custom-made for the subject. The metals that the inlay was composed of were chosen from many metal samples (Figure 6). The selection of the best kind of metal was performed as follows; first, the most ideal metal was selected by the Bi-Digital O-Ring Test [17] [18], second, when this metal was brought near the subject's body, his hip joint condition improved. The metal was judged to be ideal for the inlay after the two abovementioned conditions were met. Additionally, when placing the metal on his body, the subject's hip joint conditon had to improve as judged by the Bi-Digital O-Ring Test [17] [18]. This procedure was very important in judging whether the metals were effective in treating the subject's hip joint condition during diagnosis. No side effects were detected in the subject, and the prognosis was good, suggesting that a simple dental treatment, such as this, may be very useful for relieving hip joint symptoms. Traditional views suggest that medicines and other materials must be ingested in order to have an effect. However, this study demonstrates that merely placing an inlay on a subject's chest may have immediate and marked effects, suggesting an effect on systemic health without insertion into the body.

The actual experiment conducted in this case can be observed in the YouTube video:

"Dental treatment using an inlay for hip joint pain"

https://www.youtube.com/watch?v=NeRZEDyEOvY

(last accessed 10/Oct/2015).

\section{Conclusion}

A gold alloy inlay was used to treat the subject's hip joint symptoms, such as pain, tension, and restriction of joint movement, and no side effects were observed. This result may be explained either by the unique electromagnetic waves emitted by the inlay or by the restoration of biting conditions. Thus, a simple dental treatment,

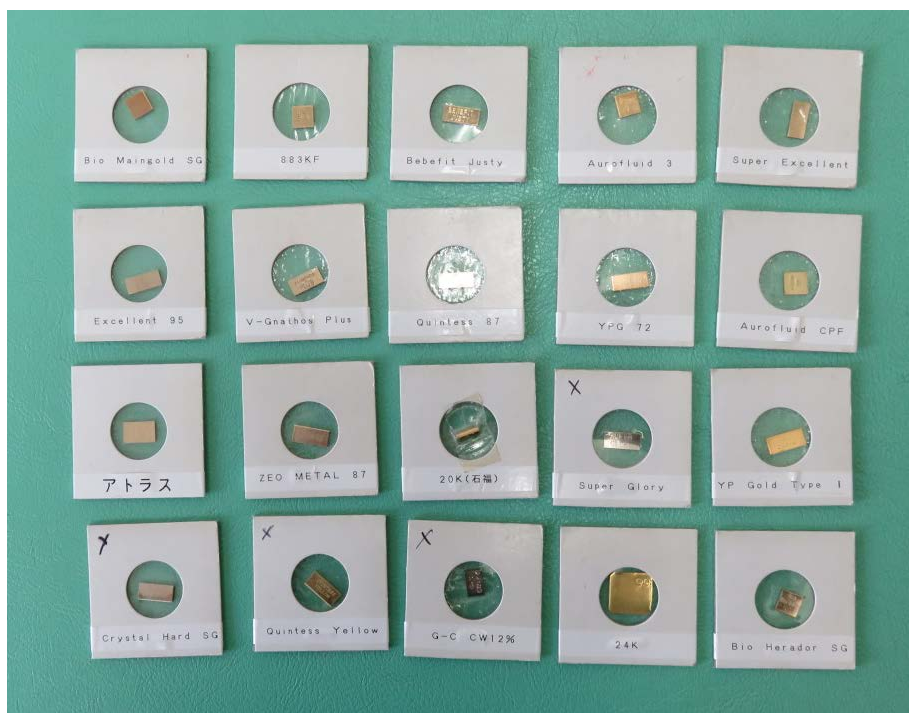

Figure 6. The metal samples. The best metal to make the inlay was selected from these metal samples. 
such as this, may help treat hip joint symptoms. However, the exact mechanism of this phenomenon is still unknown, and future multidisciplinary research focusing on this field is required.

\section{Additional Information}

Informed consent for publication was obtained from the subject.

\section{References}

[1] http://www.webmd.com/osteoarthritis/guide/hip-replacement-surgery

[2] Olsen, I., Snorrason, F. and Lingaas, E. (2010) Should Patients with Hip Joint Prosthesis Receive Antibiotic Prophylaxis before Dental Treatment? Journal of Oral Microbiology, 2, 158-160. http://dx.doi.org/10.3402/jom.v2i0.5265

[3] Daniel, D.S., Heidi, O’C. and Bryan, S.M. (2011) Dental Procedures and Subsequent Prosthetic Joint Infections: Findings from the Medicare Current Beneficiary Survey. The Journal of the American Dental Association, 142, 1343-1351. http://dx.doi.org/10.14219/jada.archive.2011.0134

[4] Watanabe, E.K., Yatani, H., Kuboki, T., Matsuka, Y., Terada, S., Orsini, M.G. and Yamashita, A. (1998) The Relationship between Signs and Symptoms of Temporomandibular Disorders and Bilateral Occlusal Contact Patterns During Lateral Excursions. Journal of Oral Rehabilitation, 25, 409-415. http://dx.doi.org/10.1046/j.1365-2842.1998.00262.x

[5] Karppinen, K., Eklund, S., Suoninen, E., Eskelin, M. and Kirveskari, P. (1999) Adjustment of Dental Occlusion in Treatment of Chronic Cervicobrachial Pain and Headache. Journal of Oral Rehabilitation, 26, 715-721. http://dx.doi.org/10.1046/j.1365-2842.1999.00448.x

[6] Sakaguchi, K., Mehta, N.R., Abdallah, E.F., Forgione, A.G., Hirayama, H., Kawasaki, T. and Yokoyama, A. (2007) Examination of the Relationship between Mandibular Position and Body Posture. Cranio, 25, 237-249.

[7] Gangloff, P., Louis, J.P. and Perrin, P.P. (2000) Dental Occlusion Modifies Gaze and Posture Stabilization in Human Subjects. Neuroscience Letters, 293, 203-206. http://dx.doi.org/10.1016/S0304-3940(00)01528-7

[8] Fujii, Y. (2015) Dental Stimulation to the Buccal Mucous Membrane Causes Lumbago: A Report of Two Cases. Case Reports in Clinical Medicine, 4, 289-296. http://dx.doi.org/10.4236/crcm.2015.48058

[9] Fujii, Y. (2015) Calling into Question the Efficacy of Evidence-Based Medicine: Is It Always the Best Approach? Is That Really the Placebo Effect? Natural Science, 7, 165-170. http://dx.doi.org/10.4236/ns.2015.74019

[10] Fujii, Y. (2012) Do Dental Implants Cause Scoliosis? Case Report. Personalized Medicine Universe, 1, 79-80. http://dx.doi.org/10.1016/j.pmu.2012.05.012

[11] Fujii, Y. (2014) Gold Alloy Dental Inlay for Preventing Involuntary Body Movements Caused by Electromagnetic Waves Emitted by a Cell Phone. Open Journal of Antennas and Propagation, 2, 37-43. http://dx.doi.org/10.4236/ojapr.2014.24005

[12] Fujii, Y. (2014) Sense of Balance Disorder Caused by Electromagnetic Waves Collected by a Dental Implant. Acupuncture and Electro-Therapeutics Research, 39, 379.

[13] Fujii, Y. (2014) Sensation of Balance Dysregulation Caused/Aggravated by a Collection of Electromagnetic Waves in a Dental Implant. Open Journal of Antennas and Propagation, 2, 29-35. http://dx.doi.org/10.4236/ojapr.2014.23004

[14] Fujii, Y. (2007) The Dental Treatment That Used Environment of Electromagnetic Wave. Acupuncture and Electro-Therapeutics Research, 32, 291.

[15] Fujii, Y. (2009) The Consideration of the Electromagnetic Wave in Dental Material Substitution. Acupuncture and Electro-Therapeutics Research, 34, 89.

[16] Fujii, Y. (2015) Dental Treatment for Dizziness and Joint Mobility Disorder Caused by Harmful Electromagnetic Waves. Open Journal of Antennas and Propagation, 3, 1-7. http://dx.doi.org/10.4236/ojapr.2015.31001

[17] Omura, Y. (1993) Bi-Digital O-Ring Test for Imaging and Diagnosis of Internal Organs of a Patient. Published 199302-23, Issued 1993-02-23. US Patent 5188107. http://academic.reed.edu/economics/parker/f11/354/pat/o-ring.pdf

[18] http://bdort.org/ 